\title{
Influence of nanofluids on the efficiency of Flat-Plate Solar Collectors (FPSC)
}

\author{
Marjan B. Nejad ${ }^{1}$, H. A. Mohammed ${ }^{2,}$, O. Sadeghi ${ }^{1}$, Swar A. Zubeer ${ }^{2}$ \\ ${ }^{1}$ Department of Thermofluids, Faculty of Mechanical Engineering, Universiti Teknologi Malaysia, \\ 81310 UTM Skudai, Johor Bahru, Malaysia \\ ${ }^{2}$ Department of Energy Engineering, Technical College of Engineering, Duhok Polytechnic \\ University (DPU), 61 Zakho Road, 1006 Mazi Qr, Duhok-Kurdistan Region, Iraq
}

\begin{abstract}
A numerical investigation is performed using finite volume method to study the laminar heat transfer in a three-dimensional flat-plate solar collector using different nanofluids as working fluids. Three nanofluids with different types of nanoparticles ( $\mathrm{Ag}$, MWCNT and $\mathrm{Al}_{2} \mathrm{O}_{3}$ dispersed in water) with $1-2 \mathrm{wt} \%$ volume fractions are analyzed. A constant heat flux, equivalent to solar radiation absorbed by the collector, is applied at the top surface of the absorber plate. In this study, several parameters including boundary conditions (different volume flow rates, different fluid inlet temperatures and different solar irradiance at Skudai, Malaysia), different types of nanoparticles, and different solar collector tilt angles are investigated to identify their effects on the heat transfer performance of FPSC. The numerical results reveal that the three types of nanofluid enhance the thermal performance of solar collector compared to pure water and FPSC with Ag nanofluid has the best thermal performance enhancement. For all the cases, the collector efficiency increased with the increase of volume flow rate while fluid outlet temperature decreased. It is found that FPSC with tilt angle of $10^{\circ}$ and fluid inlet temperature of $301.15 \mathrm{~K}$ has the best thermal performance.
\end{abstract}

\section{Introduction}

Solar energy is one of the most environmentally friendly and beneficial forms of renewable and sustainable energy. The application of solar heating systems has been developed in the past few decades in order to benefit from sustainability, reasonable initial cost and simple construction. Solar collectors are one of the most significant components of these structures. A solar collector can be considered as one of the specific type of heat exchanger that converts solar radiation or insolation into heat. Among diverse kinds of solar thermal collectors, flat-plate solar collectors have been mostly utilized. This is due to the fact that they have relatively lower cost and simpler mechanical structure [1].

Several numerical, analytical and experimental investigations on the thermal performance of flat-plate solar collector have been carried out by many authors. Dovic and

\footnotetext{
* Corresponding author: hussein.dash@yahoo.com
} 
Andrassy [2] carried out two-dimensional and three-dimensional numerical simulations of flat-plate solar water collectors with and without tubes and a corrugated plate solar collector. It was seen that the corrugated absorber plates of chevron type and the solar collectors without tubes have better thermal efficiency and performance. Jafarkazemi and Ahmadifard [3] theoretically investigated the effects of fluid flow rate, temperature, type of working fluid and thickness of back insulation on exergy and energy efficiency of flat-plate solar collector. It was concluded that using water with inlet temperature approximately $40^{\circ} \mathrm{C}$ more than ambient temperature and a lower mass flow rate enhances the overall efficiency of flat-plate solar collector. Eismann and Prasser [4] evaluated the absorber edge effect in 2D numerical simulations of a flat-plate solar collector. It was found that edge effects must be significantly taken into consideration in order to derive more precise collector efficiency and heat loss coefficients as well as material costs. Karanth et al. [5], Manjunath et al. [6] and Selmi et al. [7] carried out a 3D numerical investigation of a flatplate solar collector using Discrete Transfer Radiation (DTRM) with the help of Computational Fluid Dynamics (CFD) simulation method. It was seen that the water and absorber plate temperatures along flow length decreases with the increase of flow velocity and show similar linear trends for all the chosen velocities.

Dagdougui et al. [8] numerically and theoretically conducted thermal analysis and performance optimization of a flat-plate solar collector (FPSC). They observed that the maximum outlet water temperature decreased with the increase of water flow rate whereas the collector efficiency showed an opposite behavior. Alvarez et al. [9] and Fan et al. [10] presented experimentally, numerically and analytically thermal characteristics of conventional fin-and-tube solar collector and corrugated flow channel type of solar collector. It was observed that the efficiency of flat-plate solar collector with serpentine ducts was higher than that of parallel ducts. Tagliafico et al. [11] and Cruz-Peragon et al. [12] conducted a comprehensive review on the thermal models, CFD analysis and characterization of flat-plate solar collectors respectively. Other researchers $[13,14]$ studied the heat transfer and thermal characteristics of flat-plate solar collectors.

Inevitably, flat-plate solar water collectors have relatively low thermal efficiency and outlet temperatures. One of the practical methods for increasing solar collector efficiency is substituting the absorbing fluid, water, by high thermal conductivity fluids called nanofluids. Nanofluids are suspension of metallic or nonmetallic nanometer-sized material (nanoparticle, 1-100 $\mathrm{nm}$ ) in a base fluid such as water [15]. Nanofluids have superior thermophysical properties in comparison to conventional fluids. To illustrate, they have higher viscosity, thermal conductivity and convective heat transfer coefficients [16]. Faizal et al. [17] and Alim et al. [18] theoretically investigated the energy, economic and environmental impacts of using metal oxides nanofluid for a flat-plate solar collector. They show that $\mathrm{CuO}$ nanofluid contributes to higher solar collector efficiency and area reduction. They demonstrated that $4.34 \%$ reduction of entropy generation, $22.15 \%$ enhancement of heat transfer coefficient and $1.58 \%$ pumping power penalty when using $\mathrm{CuO}$ nanofluid compared to that of water. Yousefi et al. [19-21] carried out three different experimental analyses using MWCNT- $\mathrm{H}_{2} \mathrm{O}$ and $\mathrm{Al}_{2} \mathrm{O}_{3}-\mathrm{H}_{2} \mathrm{O}$ nanofluids in a flat-plate solar collector. They pointed out that he efficiency of flat-plate solar collector increased by $28.3 \%$ using $0.2 \mathrm{wt} \% \mathrm{Al}_{2} \mathrm{O}_{3}$ and $15.63 \%$ using $0.4 \mathrm{wt} \% \mathrm{Al}_{2} \mathrm{O}_{3}$ with surfactant compared to water. Experimental analyses on performance of a flat-plate solar collector using different types of nanofluid were carried out by Polvongsri and Kiatsiriroat [22], Said et al. [23] and Chaji et al. [24]. It was concluded that the effects of nanofluids with low volume fractions were insignificant on the pumping power and pressure drop of a solar collector. Nasrin and Alim [25] numerically examined the effects of using $\mathrm{Al}_{2} \mathrm{O}_{3}$ and $\mathrm{Cu}$ nanofluid in a solar collector having the flat-plate cover and sinusoidal corrugated absorber. 
It can be noticed from the comprehensive literature review that there are no numerical studies using computational fluid daynamics (CFD) on the thermal efficiency of FPSC using nanofluids as working fluids. Hence, this numerical study will focus on the thermal performance enhancement of flat-plate solar collector when applying three different nanofluids, namely $\mathrm{Al}_{2} \mathrm{O}_{3}, \mathrm{MWCNT}$ and $\mathrm{Ag}$ nanofluid at different volume fractions of $1-2 \%$ and $\mathrm{d}_{\mathrm{np}}=20 \mathrm{~nm}$ by means of CFD analysis and real meteorological data taken in Skudai, Malaysia.

\section{Theoretical analysis of FPSC}

\subsection{Energy analysis}

In steady state simulation, the actual useful energy output of a collector gain by the working fluid is calculated using:

$$
Q_{u}=\dot{m} C_{p}\left(T_{f o}-T_{f i}\right)
$$

where $\dot{m}$ is the inlet mass flow rate, $C_{p}$ is the heat capacity of the fluid, $T_{f o}$ is the fluid outlet temperature and $T_{f i}$ is the fluid inlet temperature.

The inlet mass flow rate of the working fluid can be determined by using:

$$
\dot{m}=\rho \dot{V}
$$

The useful energy gain by the working fluid also can be expressed in terms of heat removal factor, $F_{R}$, absorbed solar radiation, $S$, and collecor overall loss coefficient, $U_{L}$, to exhibit the effect of optical properties of the collector and heat losses. Hence, the following equations are used for the useful energy and collector efficiency [26]:

$$
\begin{gathered}
Q_{u}=A_{c} F_{R}\left[S-U_{L}\left(T_{f i}-T_{a}\right)\right] \\
S=G_{T}(\tau \alpha) \\
F_{R}=\frac{\dot{m} C_{p}}{A_{c} U_{L}}\left[1-\exp \left(-\frac{A_{c} U_{L} F^{\prime}}{\dot{m} C_{p}}\right)\right] \\
F^{\prime}=\frac{1 / U_{L}}{W\left[\frac{1}{U_{L}[D+(W-D) F]}+\frac{1}{C_{b}}+\frac{1}{\pi D_{i} h_{f i}}\right]} \\
F=\frac{\tanh [m(W-D) / 2]}{m(W-D) / 2} \\
m=\sqrt{\frac{U_{L}}{k \delta_{p}}}
\end{gathered}
$$

where $A_{c}$ is the surface area of the solar collector, $F^{\prime}$ is the collector efficiency factor and $F$ is the standard fin efficiency. $\tau \alpha$, is transmittance-absorptance product (optical properties of the collector), which is assumed to be $0.87 . T_{a}$ is the ambient temperature of Skudai, which is $301.15 \mathrm{~K}$, on October 15, 2016 and $G_{T}$ is the total incident solar irradiance on the tilted surface, which is calculated in Skudai (latitude is $1.5333^{\circ} \mathrm{N}$ and longitude is $103.6667^{\circ} \mathrm{E}$ ) on October 15 at different times of the day, based on the following correlations [26]:

$$
G_{T}=G_{b} R_{b}+G_{d}\left(\frac{1+\cos \beta}{2}\right)+G \rho_{g}\left(\frac{1-\cos \beta}{2}\right)
$$

where $G_{b}$ is the beam solar irradiance, $G_{d}$ is the diffuse solar irradiance, $G$ is the direct normal solar irradiance (total solar irradiance) on a horizontal surface $\left(G=G_{b}+G_{d}\right), R_{b}$ is 
the geometric factor (ratio of beam radiation on the tilted surface to that on a horizontal surface), $\beta$ is the collector tilt angle and $\rho_{g}$ is the ground reflectance, which is assumed to be 0.4 . The geometric factor, $R_{b}$, is calculated from the following equation:

$$
R_{b}=\frac{\cos (\phi-\beta) \cos \delta \cos \omega+\sin (\phi-\beta) \sin \delta}{\cos \phi \cos \delta \cos \omega+\sin \phi \sin \delta}
$$

where $\phi$ is latitude, $\delta$ is declination (see [26], Table 1.6.1), calculated from approximate equations [27-29] and $\omega$ is hour angle calculated from $15^{\circ}$ spin of the earth multiplied by number of hours from/to solar noon. During morning, $\omega$ has negative value and afternoon it has positive value.

The instantaneous solar collector efficiency $\left(\eta_{i}\right)$ is defined as the ratio of the useful energy gain to the total incident solar irradiance on the tilted collector surface:

$$
\begin{aligned}
\eta_{i} & =\frac{Q_{u}}{A_{c} G_{T}}=\frac{\dot{m} C_{p}\left(T_{f o}-T_{f i}\right)}{A_{c} G_{T}} \\
\eta_{i} & =F_{R}(\tau \alpha)-F_{R} U_{L} \frac{T_{f i}-T_{a}}{G_{T}}
\end{aligned}
$$

According to [19-21], $F_{R}(\tau \alpha)$ and $F_{R} U_{L}$ are called absorbed energy parameter and removed energy parameter respectively.

Convective heat transfer coefficient of the working fluid in the solar collector can be examined by:

$$
h=\frac{q^{\prime \prime}}{\left(T_{w}-T_{f}\right)}
$$

where $q^{\prime \prime}$ is actual heat flux derived from useful heat gain, $T_{w}$ is the tube average wall temperature and $T_{f}$ is average fluid temperature.

\subsection{Pressure drop and pumping power}

The constant fluid flow for flat-plate solar collector system is provided with the help of forced convection by electrical pump. The pressure drop of the solar collector is calculated from the following Darcy equation [30, 31]:

$$
\Delta P=f \frac{\rho V^{2}}{2} \frac{\Delta l}{D_{i}}+K \frac{\rho V^{2}}{2}
$$

where $K$ is the loss coefficienct owing to entrance and exit effects, bends, elbows, valves, etc and $\rho$ is the density of the fluid, $f$ is the friction factor and $V$ is the average flow velocity of the fluid $(\mathrm{m} / \mathrm{s})$ which are determined from the following equations [30, 31]:

$$
f=\frac{64}{R e}, R e=\frac{\rho V D_{i}}{\mu}=\frac{4 \dot{m}}{\pi D_{i} \mu}, V=\frac{\dot{m}}{\rho \pi D_{i}{ }^{2} / 4}
$$

The pumping power is derived from the following equation:

$$
\text { pumping power }=\left(\frac{\dot{m}}{\rho}\right) \times \Delta P
$$




\section{Numerical modeling}

\subsection{Physical model}

The schematic diagram of a flat-plate solar collector, having 6 horizontally inclined absorber (riser) tubes is shown in Fig. 1. In this study, it is assumed that the flow is distributed uniformly through 6 tubes by headers. Moreover, the header tubes are neglected due to the assumptions that they contain a small area of the solar collector [26]. Hence, the numerical model consists of one of the absorber tubes with its corresponding absorber plate (absorber fin). The cross-section of the numerical model is depicted in Fig. 2. The diameter and thickness of the tube are $0.01 \mathrm{~m}$ and $0.0009 \mathrm{~m}$. The width of the absorber plate is taken as $0.14 \mathrm{~m}$. The lengths of absorber plate and tube are considered as $1.5 \mathrm{~m}$.

Mass-flow-inlet boundary is used for inlet flow of the tube and the outlet flow is determined by pressure-outlet boundary. The solid (absorber plate) and fluid domains are bounded with the help of wall boundary conditions. The conjugate heat transfer from the tube to working fluid derives from interface wall between absorber tube and fluid with coupled thermal condition. A constant heat flux is applied at the top surface of the absorber plate. The heat flux is equivalent to solar radiation absorbed by the collector. The walls of the absorber plate (side surfaces) are assumed to be insulated. Bottom surface of the absorber plate is assumed to have free convection with $\mathrm{h}=16 \mathrm{~W} / \mathrm{m}^{2} \cdot \mathrm{K}$ and laminar flow is considered for the CFD model. Copper is selected for both absorber plate and tube material and all the thermal-physical properties are assumed constant.

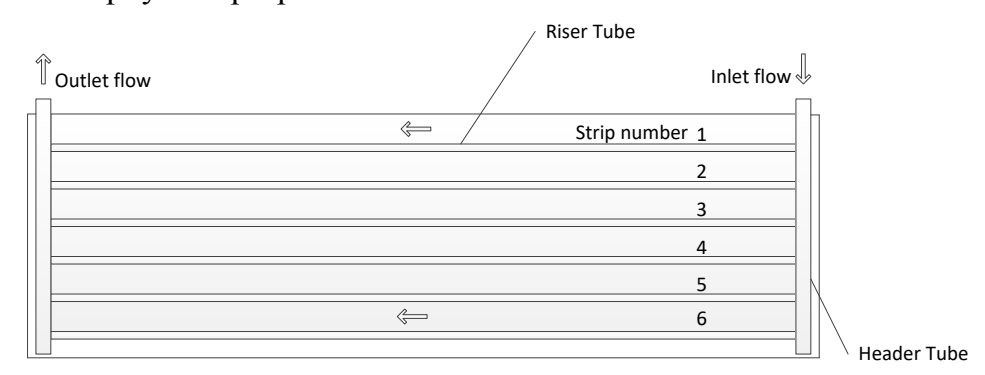

Fig. 1. Schematic diagram of the physical model.

The 3D steady state, incompressible and laminar flow governing equations of continuity, Navier-Stokes (momentum equation) and energy are considered for the case under study and are taken from Patankar [32] and its not written here because of lack of space.

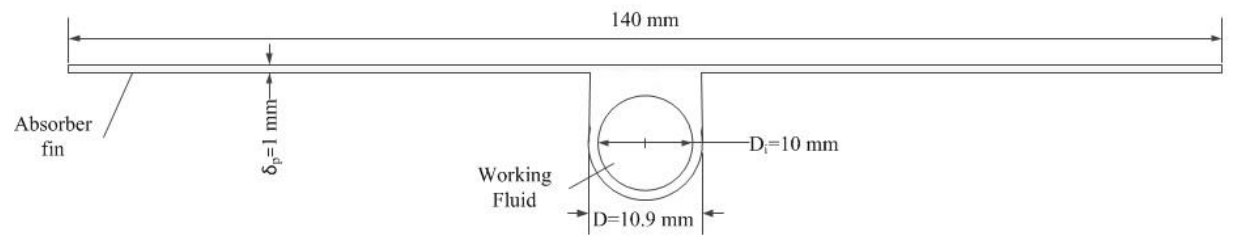

Fig. 2. Cross section of a fin-and-tube collector. 


\subsection{Grid testing and model validation}

The grid independent test was performed for a fin-and-tube collector using water as a working fluid with volume flow of $0.04 \mathrm{~L} / \mathrm{min}$ to ensure that the solution does not depend on the grid size and quality. As shown in Fig. 3a, if the number of elements for the mesh increases from 2178677 to 4284555 , the average water outlet temperature will not change significantly. Thus, the number of 2178677 elements for the non-uniform grid has been adopted for the computational analysis. Grid layout for the present numerical model is depicted in Fig. $3 b$.
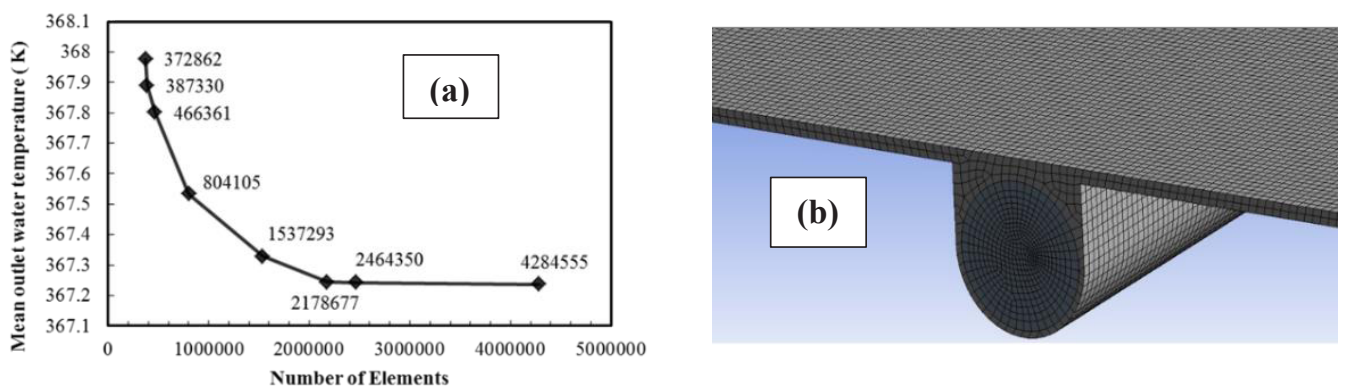

Fig. 3. (a) Grid Test for a fin-and-tube collector, (b) grid layout used in the present work.

The present numerical solution was validated by comparing the temperature distribution of absorber plate and water with the results of Manjunath et al. [6]. The validation results show a very good agreement between the two investigations as shown in Fig. 4a-b. The pressure drop throughout the solar collector obtained from the present numerical study with the correlations of Darcy [31] was also validated as shown in Fig. 4c. It is clearly seen that there is a good agreement between the numerical simulation and the analytical Darcy equation.

The thermophysical properties of nanofluids (density, heat capacity, thermal conductivity and viscosity are calculated based on the correlations given in these References [33-36].
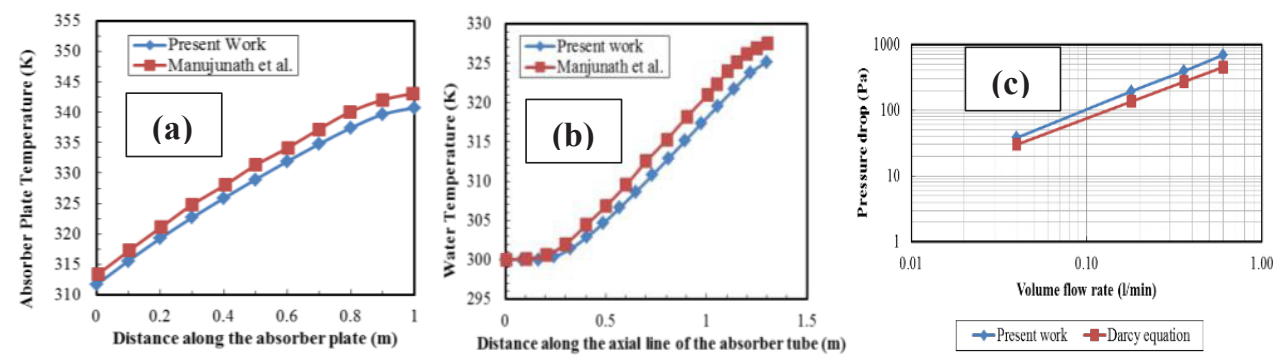

Fig. 4. Comparison of the present results with the results of Manjunath et al. [6], temperature distribution of (a) absorber plate, (b) water and (c) Pressure drop of FPSC. 


\section{Results and discussion}

\subsection{The effect of different tilt angles of solar collector}

The simulation was done using $\mathrm{Al}_{2} \mathrm{O}_{3}$ nanofluid with $1 \mathrm{wt} \%$ volume fraction. Fig. 5a and Fig. $5 \mathrm{~b}$ present the outlet fluid and absorber plate average temperatures versus the inlet volume flow rate of the fluid for different tilt angles of solar collector respectively. Clearly, when the tilt angle of solar collector increases from $10^{\circ}$ to $70^{\circ}$, the temperatures decrease. This is due to the fact that Malaysia is located near the equator and has a sunny climate; hence, its geographical coordinates lead sun to be perpendicular to the plane of the solar collector with almost small tilt angle. Consequently, the solar collector having tilt angle of $10^{\circ}$ appears to gain more useful energy as depicted in Fig. 5c. As shown in Fig. 5d, the solar collector efficiency does not change significantly with respect to tilt angle since the efficiency is defined as the ratio of the useful energy gain to the total incident solar irradiance on the tilted collector surface. Obviously, both the useful heat gain and solar irradiance increase with the decrease of collector tilt angle; thus, the ratio remains unchanged. Furthermore, it is apparent that the average temperatures decrease with the increase of volume flow rate while the useful heat gain and collector efficiency increase.
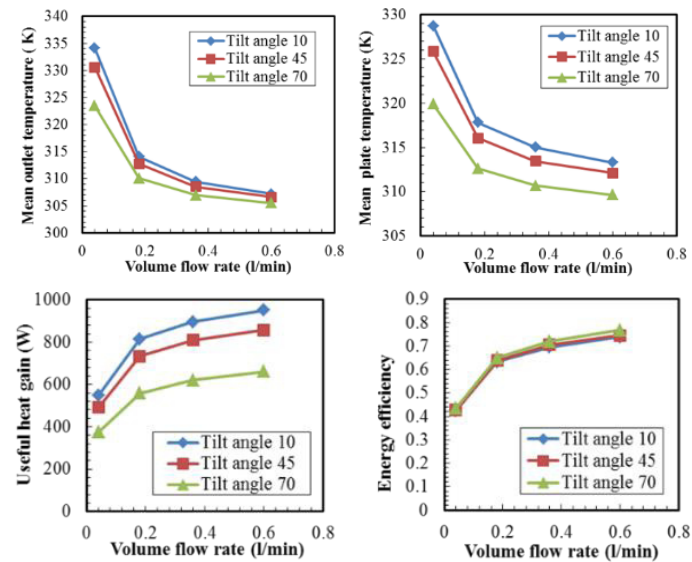

Fig. 5. Variation of (a) mean outlet fluid, (b) plate temperature, (c) useful heat gain and (d) energy efficiency with volume flow rate for different tilt angles of solar collector.

\subsection{The effect of different types of nanoparticles}

The influences of implementing three different nanoparticles, namely silver (Ag), MWCNT and $\mathrm{Al}_{2} \mathrm{O}_{3}$ dispersed in water as a base fluid with volume fractions of $1 \%$ on the thermal performance of FPSC are discussed. Fig. 6a and Fig. 6b show the outlet fluid and absorber plate average temperatures respectively, using different nanofluids and water as working fluids. The figure clearly shows that when using nanofluids rather than water as working fluids, the outlet and plate temperatures increase. Higher density and thermal conductivity and lower specific heat of nanofluids compared to that of water contribute to higher outlet temperature which in turn leads to an increment in useful heat gain and thermal efficiency as depicted in Fig. 6c and Fig. 6d. Due to the fact that Ag nanofluid has the lowest specific heat and highest density compared to other two nanofluids, it has the highest values for the temperatures and collector efficiency. 

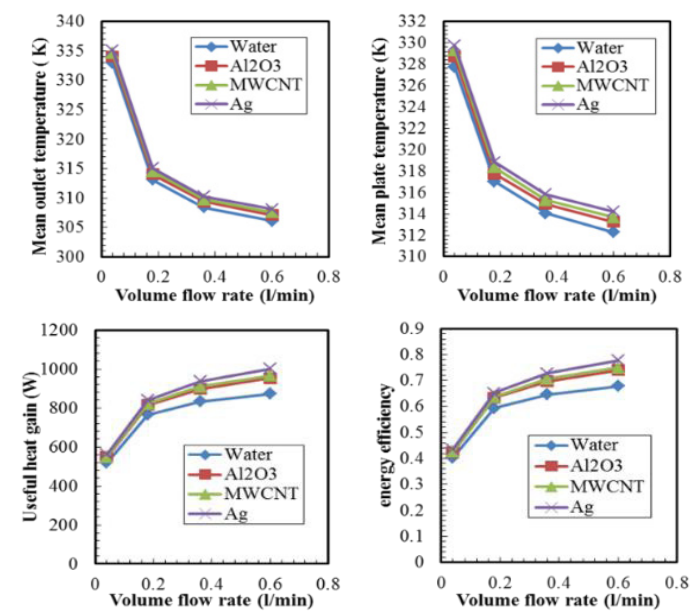

Fig. 6. Variation of (a) mean outlet fluid, (b) plate temperature, (c) useful heat gain and (d) energy efficiency with volume flow rate for different nanofluids and water.

Fig.7a shows the convective heat transfer coefficient (h) of different nanofluids and water. It is noticed that heat transfer coefficient is augmented compared with that of water. Consequently, nanofluids, which have higher thermal conductivity, gain more heat from the absorber plate; results in reduction of thermal boundary layer and hence an increase in heat transfer coefficient. Similarly, Ag nanofluid has the highest value of (h). The figure clearly reveals that (h) is increased with the increase of volume flow rate. As shown in Fig. 7b and Fig. 7c, small increments in pressure drop and pumping power are resulted when using nanofluids compared to that of water. Furthermore, increasing fluid inlet volume flow rate leads to an increase in pressure drop and consequently to an increase in pumping power.
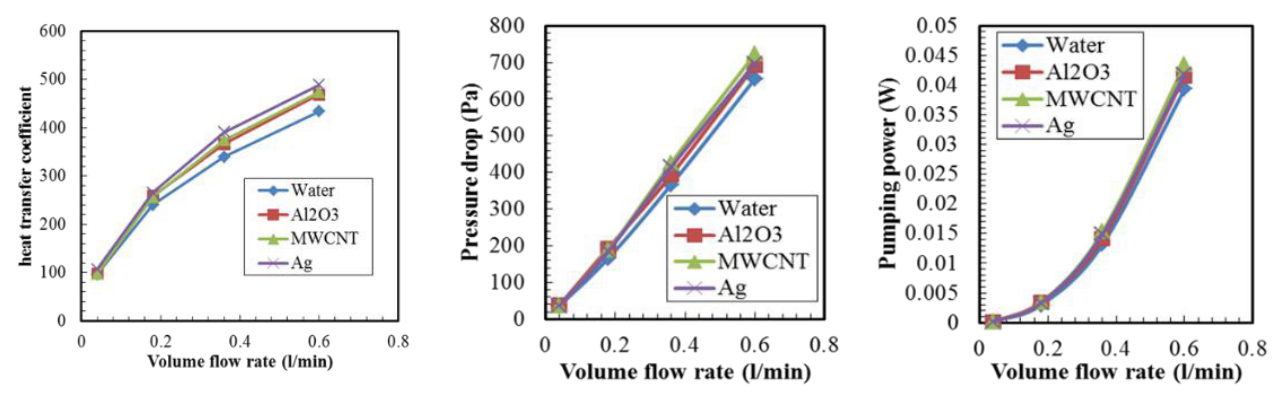

Fig. 7. Variation of (a) heat transfer coefficient, (b) pressure drop and (c) pumping power with volume flow rate for different nanofluids and water.

\subsection{The effect of different solar Irradiance at Skudai, on October 15}

The simulation was done using Ag nanofluid with $2 \mathrm{wt} \%$ volume fraction and collector tilt angle of $10^{\circ}$. Fig. 8a and Fig. $8 \mathrm{~b}$ show the outlet fluid and absorber plate average temperatures versus the inlet volume flow rate of the fluid for different times of the day and absorbed solar radiations $(S)$ respectively. Apparently, at $1 \mathrm{PM}$ with the highest $(S)$, the maximum temperatures are generated while the minimum ones are generated at $8 \mathrm{AM}$ with the lowest $(S)$. At $9 \mathrm{AM}$ and $5 \mathrm{PM}$, the values of temperatures are almost equal owing to the same values of $(S)$. The similar trend is observed for useful heat gain as shown in Fig. 8c and Fig. 8d. The solar collector efficiency does not change significantly at different times 
of the day. Due to the fact that both useful heat gain and solar irradiance change at different times of the day, the ratio virtually remains unchanged.
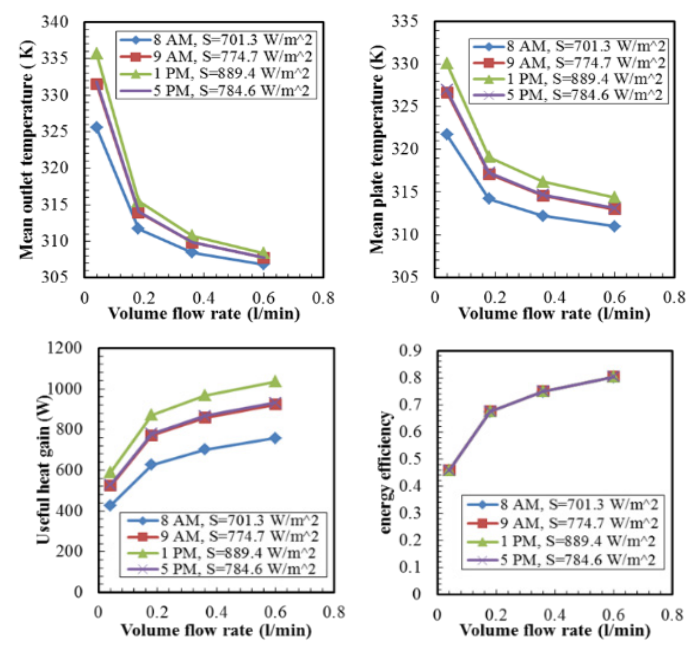

Fig. 8. Variation of (a) mean outlet fluid, (b) plate temperature, (c) useful heat gain and (d) energy efficiency with volume flow rate at different times of October 15, 2016 and absorbed solar radiation.

\section{Conclusions}

From the present numerical study on the influence of different nanofluids on the efficiency of flat-plate solar collectors, it is observed that the FPSC with tilt angle of $10^{\circ}$ shows the best thermal performance. It is also shown that with increasing inlet volume flow rate, absorber plate and fluid outlet temperature decrease while the useful heat gain, solar collector efficiency and heat transfer coefficient increase. Moreover, the pressure drop and hence pumping power increase with the increase of volume flow rate. It is concluded that the three types of nanofluid enhance the thermal performance of solar collector compared to pure water. Apparently, FPSC with Ag nanofluid shows the best thermal performance enhancement. The efficiency of solar collector using Ag nanofluid with inlet volume flow rate of $0.6 \mathrm{~L} / \mathrm{min}$ increased by $17.65 \%$ compared to that of water. A small increment in pressure drop is observed when using nanofluids. The highest solar irradiation and therefore the best thermal performance is observed at 1 PM in Skudai, Malaysia.

\section{References}

1. K. Solangi, M. Islam, R. Saidur, N. Rahim, Renew. Sust. Energy Revi. 15, 2149 (2011)

2. D. Dović, M. Andrassy, Solar Energy 86, 2416 (2012)

3. F. Jafarkazemi, E. Ahmadifard, Renewable Energy 56, 55 (2013)

4. R. Eismann, H.M. Prasser, Solar Energy 95, 181 (2013)

5. K.V. Karanth, M. Manjunath, N.Y. Sharma, Proc of World Congress on Eng. III, 6 (2011)

6. M. Manjunath, V.K. Karanth, Y.N. Sharma, Lect. Notes in Eng Comp Sci. 2192, 2245 (2011)

7. M. Selmi, M.J. Al-Khawaja, A. Marafia, Renewable Energy 33, 383 (2008) 
8. H. Dagdougui, A. Ouammi, M. Robba, R. Sacile, Renew. Sust. Energy Revi. 15, 630 (2011)

9. A. Alvarez, O. Cabeza, M. Muñiz, L. Varela, Energy 35, 3707 (2010)

10. J. Fan, L.J. Shah, S. Furbo, Solar Energy 81, 1501 (2007)

11. L.A. Tagliafico, F. Scarpa, M. De Rosa, Renew. Sust. Energy Revi. 30, 526 (2014)

12. F. Cruz-Peragon, J. Palomar, P. Casanova, Renew. Sust. Energy Revi. 16, 1709 (2012)

13. O. Turgut, N. Onur. Int. Commu. Heat Mass Transfer 36, 274 (2009)

14. N. Akhtar, S. Mullick, Solar Energy 66, 349 (1999)

15. S. Choi, ASME-Publications-Fed 231, 99 (1995)

16. K.V. Wong, O. De Leon, Advances in Mechanical Engineering 20, 240 (2010)

17. M. Faizal, R. Saidur, S. Mekhilef, M. Alim, Energ. Conver. Manag. 76, 162 (2013)

18. M. Alim, Z. Abdin, R. Saidur, A. Hepbasli, Energy and Buildings 66, 289 (2013)

19. T. Yousefi, E. Shojaeizadeh, F. Veysi, S. Zinadini, Solar Energy 86, 771 (2012)

20. T. Yousefi, F. Veisy, E. Shojaeizadeh, S. Zinadini, Exp. Therm. Flui. Sci. 39, 207 (2012)

21. T. Yousefi, F. Veysi, E. Shojaeizadeh, S. Zinadini, Renewable Energy 39, 293 (2012)

22. S. Polvongsri, T. Kiatsiriroat, Heat Transf. Eng. 12, 250 (2013)

23. Z. Said, M. Sajid, R. Saidur, N. Rahim, Int. Commu. Heat Mass Trans. 48, 99 (2013)

24. H. Chaji, Y. Ajabshirchi, E. Esmaeilzadeh, M. Kahani, Modern Applied Science 7, 60 (2013)

25. R. Nasrin, M. Alim, Heat Transfer-Asian Research 43, 61 (2014)

26. J.A. Duffie, W.A. Beckman, Solar Engineering of Thermal Processes (2006)

27. P. Cooper, Solar Energy 12, 333 (1969)

28. J. Spencer, Search 2, 172 (1971)

29. M. Iqbal, An introduction to solar radiation (Elsevier, 1983)

30. H. Garg, R. Agarwal, Energ. Conver. Manag. 36, 87 (1995)

31. F. White, Fluid Mechanics (5th edt., 2003)

32. S.V. Patankar, D.B. Spalding, Int. J. of Heat Mass Transfer 15, 1787 (1972)

33. Y. Xuan, W. Roetzel, Int. J. Heat Mass Transfer 43, 3701 (2000)

34. S.Q. Zhou, R. Ni, Applied Physics Letters 92, 093123 (2008)

35. S.M. Vanaki, H.A. Mohammed, A. Abdollahi, M. Wahid, J. Mol. Liq. 196, 32 (2014)

36. H.A. Mohammed, A.A. Al-aswadi, H.I. Abu-Mulaweh, Heat Trans-Asian Res. 40, 287 (2011) 